\title{
Energy Kite, a breakthrough wind generator: an Overview
}

\author{
Yash Muthe ${ }^{* *}$, Suhas Mali ${ }^{\ddagger}$ and Vikram Kolhe ${ }^{\dagger}$ \\ †Mechanical Department, Sandip Institute of Engineering \& Management, Nasik, Maharashtra, India \\ Accepted 01 Sept 2016, Available online 02 Sept 2016, Vol.6, No.5 (Oct 2016)
}

\begin{abstract}
This paper provides an overview of Energy Kites, a revolutionary technique of power generation. With growing technological innovations \& carbon footprints, energy at a cheaper rate with negligible green house effect have become vital. Leading energy companies are showing great concern to this idea of energy generation \& hence a revolution has set out for a breakthrough technological solution for this problem. Out of all innovative ideas one major idea that's gaining great attention is Airborne wind energy. Replacing the traditional structure of wind turbine by Kites tethered to ground is the main idea behind Airborne wind energy. Airborne wind technology gives a power output of $600 \mathrm{KW}$ with wind speed of $11.5 \mathrm{~m} / \mathrm{sec}$ which can be increased significantly by achieving great altitudes unliketraditional structures that are limited to height of few meters.Also due to absence of bulky tower \& huge blades,energy Kite offers much more mass to power ratio. This energy generation gives a promising power output from wind making complete use of air velocity at an comparatively higher altitude. Google has nearly invested \$15 million in the Makani power for airborne wind energy.
\end{abstract}

Keywords: Airborne, Energy Kite, Tether.

\section{Introduction}

In this Airborne technology the whole design of a traditional wind turbine is replaced by Energy Kite which traces the path of tip of a turbine eliminating $90 \%$ of weight as shown in fig.1. The Kites are installed with turbines or DC motors on the board that generate energy by taking advantage of the circular trajectory. When a Kite is flying at a great velocity in cross wind direction, the tension in the lines increases significantly. So Kite is tethered to ground station by a strong carbon fibre.

The power generated by energy Kite on board while in its circular trajectory is transmitted to ground at the same time via a high voltage wire inserted inside tethering material to ground station. This system reduces the need of gear box hence reducing the complexity \& weight of the system. Due to generation of electricity by the motors on the Kite board while in trajectory, energy Kites are also called as on-board power generator.

Available wind energy density at an altitude of 400 meters is nearly in order of two in magnitude as compared to those on the ground which have an average turbine height of 50 meters. Hence the height at which Energy Kites fly, the magnitude of wind velocities increases remarkably as compared to the traditional wind turbine (Diehl 2013).

\section{Background of Energy Kites}

The idea of power generation using tethered Kites in cross wind direction was first investigated by an American engineer Miles Loydin in 1970's \& 1980's (Diehl 2013),(Loyd 1980). He suggested two methods which he termed as lift mode \& drag mode for power generation. The motivation behind Airborne wind turbines is the fact that only $30 \%$ of the outer part of turbine blades of traditional air turbine contributes to nearly half of the total power generation, whereas these parts are much lighter as compared to inner parts of the turbine.

When a paper Kite flies in crosswind direction unlike that of a plane wind, it starts rotating in circular path similarly when a huge Kite tethered to ground flies in a crosswind direction after achieving certain altitude this Kite also obtains a circular trajectory. This trajectory is used for power generation either by using the tension in tethered rope called as lift mode or by using motors on the Kite called as drag mode. Kite used in drag mode is called as Energy Kite.

\section{Constructional details of Kite System}

Energy Kite system consist of three main components

- $\quad$ Energy Kite

- Tether

- Ground Station 


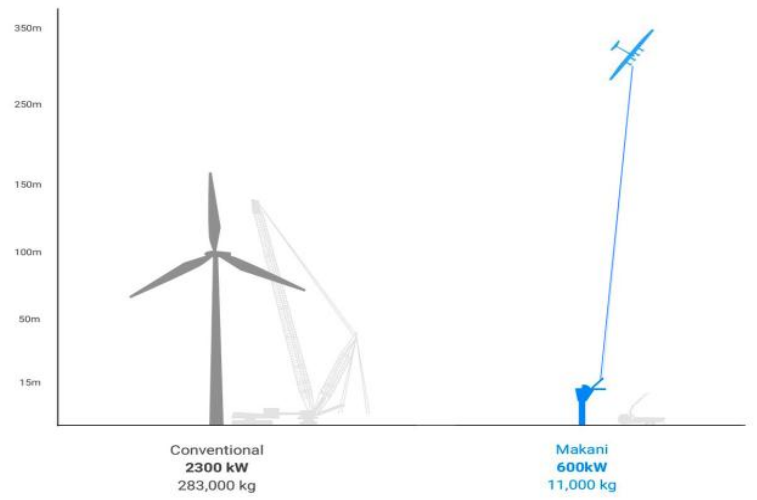

Fig.1 Basic Idea of Energy Kites (Makani Power 2016)

Flying an Energy Kite in crosswind direction is a complex control task that requires a sophisticated technology to sustain a stable orbit. Hence a computer system assisted by GPS and other sensors along with thousands of real-time calculations are required to guide the Kite to the flight path \& sustain in the strongest winds for maximum energy generation.

\subsection{Energy Kite}

Kite is the main component of entire Airborne on-board power generation system as it consists of small turbines mounted on it that generate power right on the flight by using the velocity of wind at high altitude \& directly sends it to the ground. Kite construction consists of crucial design along with selection of material that is light as well as strong.

To achieve more efficient power generation, a Kite is mounted with more than one rotor. The main objective behind installing maximum number of rotors on the Kite is to get maximum power generation as increase in rotor increases power output significantly. Makani powers in California uses a Kite with 8 rotors that effectively generates a power of $600 \mathrm{KW}$ at a wind speed of $11.5 \mathrm{~m} / \mathrm{sec}$ as shown in fig 2 .

Theoretically, a modern wing with a lift of coefficient of lift 0.03 and a wind velocity of $V_{W}=13 \mathrm{~m} / \mathrm{s}$ would lead to a power output of $217 \mathrm{KW}$ per square meter of area (Diehl 2013). Kite design consist of various challenges like the rigidity of the material to sustain various types of forces acting on it, as the Kite rotates at a very high speed. The main force that the Kite has to withstand is the drag force.

As the tether distance increases the drag force on the Kite increases too. As the drag force increases, power generation rate also increases whereas if this exceeds a limit may lead to minor instability of the system. However if such conditions exceeds their threshold then it cannot be controlled from ground station. To overcome the problem of long length of tethering \& get efficient power generation at short tethering distance, multiple Kites are used as in fig 3. This concept indeed leads to significant reduction in tether drag loss as compared to a single wing system (Wellicome 1985).

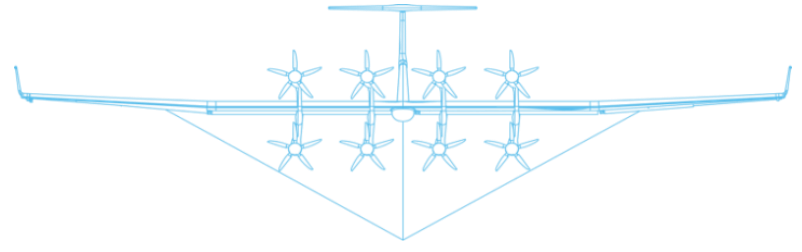

Fig.2 Design of Energy Kite (Makani Power 2016)

\subsection{Tether}

A tether is made of conductive wires surrounded by a high strength covering. The tether in case of energy Kites serves two purposes; firstly it acts as a link for Kite to ground contact and secondly used to transmit energy generated by energy Kite to the ground station.

Tether length is a crucial factor to be controlled for adjusting Kite rotation speed as well as drag acting on both the Kite as well as tether. A tether is preferably made of high strength composite fibre covering thick Aluminium wire which acts as a conductor to transfer energy from Kite to ground station.

\subsection{Ground Station}

The ground station holds the tether, and is used as a resting place for the energy Kite, when not in flight. The ground station occupies less ground space and is significantly smaller than traditional wind turbines. The ground station is directly posed to the forces acting on Kite. The ground station strength actually decides the length up to which the Kite can be tethered.

\section{Operating Principle of Energy Kite}

Power $\mathrm{P}$ that can be generated by the Energy Kite under idealised assumption can be approximately given by equation 1 .

$$
P=\frac{2}{27} \rho \mathrm{A} V_{W}^{3} C_{L}\left(\frac{C_{L}}{C_{D}}\right)^{2}
$$

Where; $A$ is the area of Kite wing , $C_{L} \& C_{D}$ are the lift \& drag coefficient respectively \& $V_{W}$ is the wind speed. A ratio of lift coefficient $\mathrm{C}_{\mathrm{L}}$ to that of drag coefficient $\mathrm{C}_{\mathrm{D}}$ is the drag ratio which is an important aspect with respect to power generation. Importance of drag ratio is clearly reflected in equation 1 (Diehl 2013). Initially the Kite is taken to a considerable height by the on board rotors attached to the Kite, which are powered by electricity from the ground station. These rotors take Kite up to a suitable altitude where Kite gets into its circular trajectory in crosswind direction \& faces high velocity winds. After this stage the same rotor generates energy when Kite gets into circular motion. Setting a Kite in it's perfect trajectory needs skilled operator on the ground station.

The tether length is adjusted such that the drag pressure does not exceed the permissible capacity of force of ground station. Tether length plays an 
important role in setting diameter of rotation of the Kite, as this significantly affects the power generation. As Kite depicts, the motion of the tip of a turbine blade of a traditional wind turbine plant hence it can be visualised by this view that at set diameter of rotation of conventional turbines the power generated is strictly based on the wind speed at that particular height. But with Energy Kite a whole new possibilities opens up, as we can vary the diameter \& altitude in order to optimize power generation by minimum altitude. Also we can extract maximum power from the wind energy.

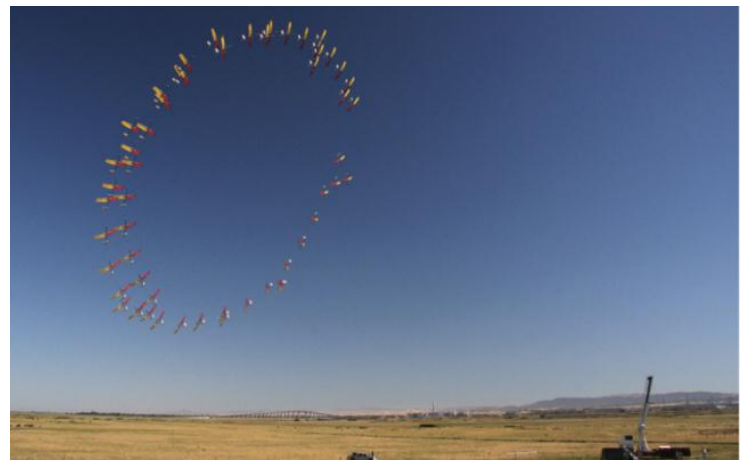

Fig.3 Application of multiple wing AWE (Smart City Studio 2016)

The total aerodynamic force that the Kite experiences is also accompanied by one more factor other than $\mathrm{C}_{\mathrm{L}}$ \& $\mathrm{C}_{\mathrm{D}}$, this factor is due to on board rotors of the Kite which generate energy. This coefficient is denoted by $\mathrm{C}_{\mathrm{D} \text {,power }}$ and might be used for usable power generation. Hence in case of energy Kite $C_{R}$ is abbreviated as aerodynamic force coefficient which is an important factor affecting power generation. While the Kite is following it's circular trajectory, it has to go through two losses: cosine loss \& gravitational loss. Gravitational loss may be neglected at high wind speeds but the cosine loss is considerable at any given moment of flight.

$$
P_{\text {wind }}=V_{W} F_{a} \operatorname{Cos} \gamma
$$

The above equation 2 indicates the total power $\mathrm{P}_{\text {wind }}$ that a flying wing extracts from this wind field is given by the product of velocity of wind $V_{w}$ with the total aerodynamic force $\mathrm{F}_{\mathrm{a}}$ that the wing experiences and the cosine of the angle $\gamma$ between the direction of this force and the wind (Diehl 2013). If the angle is kept near about 45 degrees then cosine losses may reduce up to $30 \%$ or less, while we aim at keeping this angle minimum so that cosine of $\gamma$ should remain close to 1 , it is ideally up to 20 degrees which keeps cosine loss $6 \%$ which is considerable(Diehl 2013),(Loyd 1980).

\section{Limitations of Energy Kites}

If an Energy Kite is assumed with wing area $\mathrm{A}$, aerodynamic coefficient $C_{L} \& C_{D}$ moving in a wind field of constant wind velocity $V_{W}$ with air density $\rho$ then the Kite is influenced by various forces like it's intrinsic lift , drag and on board turbine $C_{D \text {,power }}$ as well as other non aerodynamic forces like the tether resistance. These resistance factors to air reduce the total usable power that can be harvested to a great extent.

Hence Total usable power is given by a equation which include all such factors like $C_{R}, C_{L} \& C_{D}$. Due inclusion of non aerodynamic forces like tether resistance the total usable power may be less than power derived. Though this loss of usable power is significant it can be reduced if the aerodynamic force are kept in line with wind direction when wing drag is the only loss and if the air speed on the wing equals a velocity which is twice the product of $C_{R}$ and $v_{W}$ this whole value is divided by three times the coefficient of drag(Loyd 1980).

\section{Comparison with other Renewable Resources}

By comparing the power generation density of Energy Kites with current techniques of conventional power generation reflects the Energy Kite's benefit in terms of power generation per unit area. Where Energy Kite gives a power output of near about $40 \mathrm{KW} / \mathrm{m}^{2}$ at a wind speed of just $13 \mathrm{~m} / \mathrm{sec}$.

When power generation density of energy Kite is compared with photovoltaic cell, the results shows great variation. As the total solar irradiation density on earth is $1.3 \mathrm{KW} / \mathrm{m}^{2}$ but the overall efficiency of photovoltaic cell is yet limited to near about $25 \%$.There seems to be no dearth of land for solar power projects, with more than $467,021 \mathrm{sq} \mathrm{km}$ of wastelands in the India(Balachandran and Punit 2015) whereas the power generation of energy Kite is 150 times more than photovoltaic cell with much less land requirement.

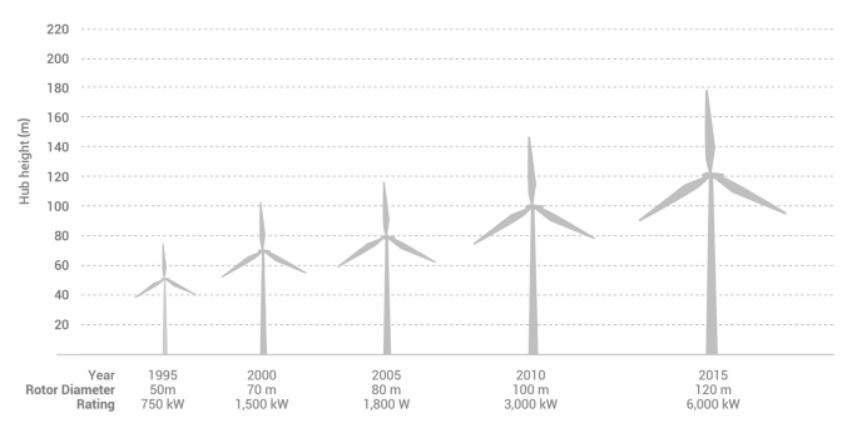

Fig.4 Power Generation by Wind Turbines (Makani Power 2016)

If Energy Kite is compared with a conventional wind turbine structure, the results show the future of wind power generation. Power generation by traditional wind turbines is increasing to a great extent every year as seen in Fig.4. This power output has increased to such levels at a cost of increase in rotor diameter as well as high cost to build such a huge structure. But the interesting part is that mass of only 39 tons of Energy 
Kite generate $30 \mathrm{MW}$ with wing area of $845 \mathrm{~m}^{2}$. This energy generation of $30 \mathrm{MW}$ equals to power output of four largest wind turbines in the world EnerconE-126, each with a rated power output of 7.5MW(Diehl 2013). Each Blade of these turbines has a weight of 65 tons and a rotor diameter of 126 meter. Hence total weight of twelve blade of these four turbines when calculated goes to 780 tons. If the weight of tower is added then the total weight goes up to 12,400 tons.

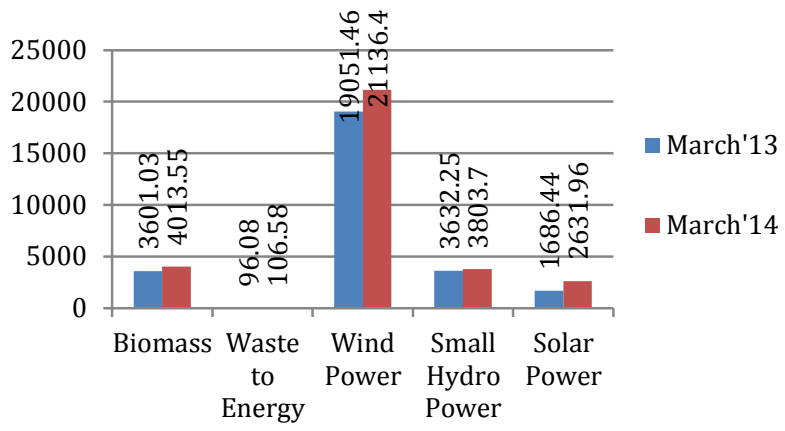

Graph.1 Installed Capacity of Grid Interactive Renewable Power in India as on 2013-2014 (Energy Statistics of 2015)

The significant weight difference of wind turbine of the order of 200 times as compared to energy Kite for same amount of power generation, holds the wind turbines Anachronistic. This is where the Energy Kites are greatly to affect the human life by reducing cost of power generation as well as need for bulky structure that occupies great usable space.

\section{Opportunities and Scope in Energy Kites}

Although investment made by Google of approx. $\$ 15 \mathrm{~m}$ in Makani power shows great interest of many huge companies in Airborne wind energy technology, but the race is also joined by many other companies. Altaeros recently received additional funding from RNT. Tata Power, a Tata Group subsidiary, is the leading developer of wind energy projects in India. Based on Airborne technology, Altaeros has designed the BAT to generate consistent, low cost energy for remote power and micro-grid market, which is currently served by expensive diesel generators. Also many other firms are showing great interest in Airborne wind energy Technology.

Number of emerging companies shown interest in this technology while attending the AirBorne wind Energy Conference, 2013

- Altaeros Energies, Boston

- SkySail , Germany

- Fraunhofer IWES, Germany

- Sky Wind Power, California

- EnerKite,Germany

- Alula Energy, Finland

- KITEnrg, Italy
Many researchers \& students from technical universities have suggested various Modern Techniques \& Strategies applied currently in AirBorne Energy Kite Technology. This conference showed the concern of whole world about electricity generation by Energy Kites (Airborne Wind Energy Conference 2013).

\section{Summary}

Current best estimates for this technology, projects a life cycle cost of 0.5 to 1.5 cents per Kilowatt hour compared to traditional wind turbine which current costs 5 to 12 cents per kilowatt hour.

Use of Energy Kites opens a new world of opportunities in the field of wind power generation by making complete use of air at high altitude too. If such technology is implemented on a large scale, the use of power plants that burn out conventional resources could be decreased to a great extent, thereby decreasing air pollution.

With Energy Kites, when electric power will be available at cheaper rates, the day of electric cars is not much far.

Use of this clean energy will decrease the rate of global warming significantly.

If more Research is carried out in the field of Energy Kites, the power generation rate may also be increased to more than $40 \mathrm{KW} / \mathrm{m}^{2}$ of wing area.

\section{References}

Moritz, Diehl. 2013. Airborne Wind Energy: Basic Concepts and Physical Foundations

http://homes.esat.kuleuven.be/ highwind/wpcontent/uploads /2013/08/Diehl2013a.pdf

Loyd, M., 1980, Crosswind Kite Power, Journal of Energy, 4(3):106-111.

Mario, Zanon, Sebastien Gros, Johan Meyers and Moritz Diehl. 2012, Airborne Wind Energy Based on Dual Airfoils, In Proceedings of the 19th IFAC World Congress, 2014, 5814-5819.

Bryan, Roberts, David Shepard, Ken Caldeira, Elizabeth Cannon, David Eccles, Albert Grenier, and Jonathan Freidin

Harnessing High-Altitude Wind Power Paper

presented at the IEEE Transactions on Energy Conversion, March 2007 d.o.i 10.1109/TEC.2006.889603

Wellicome, J., F, 1985,Some comments on therelative merits of variouswind propulsion devices, Journal of Wind Engineering and Industrial Aerodynamics 20(1-3): 111-142.

Goldman, A.,2011, Everything I Know About Marketing I Learned from Google, McGraw Hill Professional.

Airborne Wind Energy Conference 2013 http://www.awec2013.de/pdfs /

Cristina, L.A., and Caldeira,K. 2009 Global Assessment of HighAltitude Wind Power. Energies (2): 307-319. doi:10.3390/en20200307

Ahrens, Uwe, Diehl Moritz, and Schmehl, Roland. 2013. Airborne Wind Energy.

Balachandran,M and Punit,I. 2015. Why India's Solar Sector Has Turned Into A \$100 Billion Investment Magnet., Quartz India June 25.

http://qz.com/434890/why-indias-solar-sector-has-turnedinto-a-100-billion-investment-magnet/

Manna, G., Chhabra, B., Rathore, G., Kumar,S, and Hada, A. Energy Statistics of 2015, Twenty Second Issue by Central Statistics Office.

http://mospi.nic.in/mospi_new/upload/energy_stats_2015_26m ar15.pdf

Maknai Power. 2016. https://www.google.com/makani/ SmartCityStudio. 2016

http://smartcitystudio.com/tag/makani-power/ 